\title{
Assessment of implant-prosthetic therapy in relation to biomechanical indices
}

\author{
Evaluarea terapiei implanto-protetice în raport cu indicii biomecanici
}

\begin{tabular}{c} 
Michael Vitzu1, Emilian Hutu², Raluca Monica Comăneanu², \\
Alexandru Daniel Referendaru1, Marius Mariş̧ \\
1Şcoala Doctorală Medicină Dentară, Universitatea „Titu Maiorescu“, Bucureşti, România \\
${ }^{2}$ Facultatea de Medicină Dentară, Universitatea "Titu Maiorescu“, Bucureşti, România \\
\hline
\end{tabular}

\begin{abstract}
Objectives. The objective of our study was the retrospective assessment of the failure rate of implant-prosthetic treatment in a group of patients in correlation with Renouard-Rangert biomechanical scoring 2 years after prosthetic loading.

Material and method. The study material was represented by the data taken from the observation and treatment sheets of 323 patients. After applying the inclusion and exclusion criteria from the study, 297 observation and treatment sheets were selected, from which were taken data that were processed and statistically correlated with Microsoft Excel 2016.

Results. The final group included 127 male patients and 170 female patients, aged between 25 and 74 years. The 55-64 age group was best represented, and the location of the edentulous gaps was predominantly unimaxillary (236 unimaxillary edentulous patients vs. 61 bimaxillary edentulous patients). 1627 implants were inserted, of which 47 did not have a secondary stability favorable to prosthesis and were explanted. After applying prosthetic restorations, patients presented for control every 6 months in the first year and then annually. The complications of the implant-prosthetic therapy instituted were represented by decimation, loosening of the fixing screws, fracture of the physiognomic component or bone resorption passing through the first coil of the implant.

Discussions. In the studied group, although the Renouard-Rangert biomechanical score initially calculated was "green", at 2 years there were complications in $23.9 \%$ of patients, mainly due to the development of parafunctions or changes in the occlusion plan, as a result of dento-periodontal damage to other masticatory units. The change in biomechanical scoring was found mainly in women (48 cases, representing 67.6\%). To validate the results, we recommend extending the batch and the dispensing period.

Conclusions. The high percentage of therapeutic complications that occurred at 2 years that determined the change of the Renouard-Rangert biomechanical score $(95.77 \%)$ demonstrates a statistically significant correlation between the 2 parameters.
\end{abstract}

Keywords: dental implant, therapeutic complications, biomechanical score

\section{REZUMAT}

Obiective. Obiectivul studiului nostru a fost aprecierea retrospectivă a ratei de eşec al tratamentului implanto-protetic la un lot de pacienţi în corelaţie cu scoringul biomecanic Renouard-Rangert la 2 ani de la încărcarea protetică. Material şi metodă. Materialul de studiu a fost reprezentat de datele preluate din foile de observaţie şi tratament pentru 323 de pacienţi. După aplicarea criteriilor de includere şi de excludere din studiu, dintre cele 323 de fişe de observaţie şi tratament, au fost selectate 297, din care au fost preluate date care au fost prelucrate şi corelate statistic cu Microsoft Excel 2016.

Rezultate. Lotul final a cuprins 127 pacienţi de sex masculin şi 170 pacienţi de sex feminin, cu vârste cuprinse între 25 şi 74 ani. Grupa de vârstă 55-64 ani a fost cel mai bine reprezentată, iar localizarea breşelor edentate a fost preponderant unimaxilară (236 pacienţi edentaţi unimaxilar vs. 61 pacienţi edentaţi bimaxilar). Au fost inserate 1627 implanturi, dintre care 47 nu au avut o stabilitate secundară favorabilă protezării şi au fost explantate. După aplicarea restaurărilor protetice, pacienţii s-au prezentat la control din 6 în 6 luni în primul an şi, ulterior, anual. Complicațiile terapiei implanto-protetice instituite au fost reprezentate de decimentare, slăbirea şuruburilor de fixare, fractura componentei fizionomice sau resorbţia osoasă ce trece de prima spiră a implantului.

Discuții. La lotul studiat, deşi scorul biomecanic Renouard-Rangert calculat iniţial a fost „în verde“, la 2 ani, s-a constatat apariţia complicaţiilor la $23,9 \%$ dintre pacienţi, în principal din motive legate de dezvoltarea unor parafuncţii sau de modificări ale planului de ocluzie ca urmare a afectării dento-parodontale a altor unităţi masticatorii. Modificarea scoringului biomecanic s-a întâlnit preponderent la femei (48 cazuri, reprezentând 67,6\%). Pentru validarea rezultatelor, recomandăm extinderea lotului şi a perioadei de dispensarizare.

Concluzii. Procentul crescut de complicaţii terapeutice survenite la 2 ani care a determinat modificarea scorului biomecanic Renouard-Rangert (95,77\%) demonstrează o corelaţie semnificativă statistic între cei 2 parametri.

Cuvinte cheie: implant dentar, complicaţii terapeutice, scor biomecanic 


\section{INTRODUCERE}

Una dintre cele mai mari provocări ale stomatologiei moderne este protezarea edentaţiei cu sprijin implantar, care, deşi este folosită în prezent la scară largă şi are o rată semnificativă de succes, comportă o serie de riscuri [1-4] ce pot duce la eşecul tratamentului.

În anul 1990, Franck Renouard şi Bo Rangert [5] au propus noţiunea de scoring al factorilor de risc biomecanici ai tratamentului implanto-protetic, în vederea evitării posibilelor complicaţii şi creşterii ratei de succes terapeutic.

Factorii de risc biomecanici Renouard-Rangert [5] sunt cuantificaţi sub formă de valori numerice şi sunt utilizaţi pentru calcularea scorului biomecanic iniţial şi final al tratamentului.

Cele 5 categorii de factori de risc luaţi în calcul sunt:

a) Factori de risc geometrici: numărul implanturilor, realizarea unei solidarizări între dinţii naturali restanţi şi implanturi prin intermediul restaurării protetice, dispunerea implanturilor sub formă de tripod, eventuale extensii ale restaurărilor protetice, înălţime prea mare a coroanelor protetice comparativ cu lungimea implanturilor, dispunerea implanturilor excentric faţă de centrul viitoarelor coroane protetice.

b) Factori de risc ocluzali: bruxism, parafuncţii, lateralitate ghidată numai pe dinţi naturali sau lateralitate ghidată numai pe restaurarea cu sprijin implantar.

c) Factori de risc legaţi de osul alveolar şi de implanturile în sine: densitate osoasă redusă, stabilitate primară deficitară a implantului, utilizarea unui implant cu diametru mic.

d) Factori de risc tehnici: restaurări protetice cimentate, adaptare necorespunzătoare sau restaurări înşurubate deficitar.

e) Eventuale semnale de alarmă: decimentări repetate sau slăbirea repetată a şuruburilor de fixare, fractura repetată a placajului fizionomic al restaurării, fractura şuruburilor sau bonturilor protetice, resorbţie osoasă ce trece de prima spiră a implantului.

Scorul biomecanic este suma algebrică a tuturor factorilor de risc şi poate fi:

- mai mic decât 2 (,verde“), cu un prognostic terapeutic bun

- cu valoare 2 sau 3 (,galben“), ceea ce reprezintă un semnal de alarmă
- cu valoare mai mare de 3 (,roşu“), cu un prognostic terapeutic pe termen lung mai puţin bun.

\section{OBIECTIV}

Obiectivul studiului nostru a fost aprecierea retrospectivă a ratei de eşec a tratamentului implanto-protetic la un lot de pacienţi în corelaţie cu scoringul biomecanic Renouard-Rangert la 2 ani de la încărcarea protetică.

\section{MATERIAL ŞI METODE}

Materialul de studiu a fost reprezentat de datele preluate din foile de observaţie şi tratament pentru 323 de pacienţi care s-au adresat către 2 clinici de medicină dentară din Bucureşti în perioada ianuarie 2012-decembrie 2018.

Criteriile de includere în studiu au fost:

- pacienţi majori, care prezentau edentaţii parţiale

- pacienţi care au beneficiat de tratament complex implanto-protetic fix

- pacienţi care nu au întrerupt tratamentul

- pacienţi care s-au prezentat la controalele planificate după efectuarea încărcării ocluzale.

Criteriile de excludere din studiu au fost: pacienţi care au întrerupt din diferite motive tratamentul şi pacienţi care nu s-au mai prezentat la şedinţele de evaluare planificate după încărcarea ocluzală.

După aplicarea criteriilor de includere şi de excludere din studiu, dintre cele 323 de fişe de observaţie şi tratament, au fost selectate 297 , din care au fost preluate date precum sexul pacienţilor, vârsta acestora, localizarea edentației, numărul de dinţi absenţi, numărul de implanturi inserate, tipul de restaurări protetice confecţionate, modul de agregare al restaurărilor protetice, eventualele complicaţii ale tratamentului, scoringul biomecanic propus de Renouard şi Rangert imediat şi la 2 ani, care au fost introduse într-un fişier tip bază de date în Microsoft Excel 2016. Totodată, s-au realizat corelaţii statistice între parametrii analizaţi.

Deoarece studiul a fost de tip retrospectiv, nu a necesitat avizul Comisiei de Etică din cadrul Universităţii „Titu Maiorescu“ din Bucureşti. 


\section{REZULTATE}

Din totalul de 297 fişe de observaţie şi tratament rămase în studiu, 127 au fost ale unor pacienţi de sex masculin şi 170 au fost ale unor pacienţi de sex feminin, cu vârste cuprinse între 25 şi 74 ani.

Pe grupe de vârstă, distribuţia lotului a fost următoarea: în grupa de vârstă 25-34 ani, au fost 10 pacienţi (reprezentând 3\% din total, dintre care 8 femei şi 2 bărbaţi), în grupa de vârstă 35-44 ani, au fost 57 de pacienţi (reprezentând 19\% din total, dintre care 34 femei şi 23 bărbaţi), în grupa de vârstă 45-54 ani, au fost 90 de pacienţi (reprezentând $30 \%$ din total, dintre care 53 femei şi 37 bărbaţi), în grupa de vârstă 55-64 ani, au fost 112 pacienţi (38\% din total, 59 femei şi 53 bărbaţi), iar în grupa de vârstă $65-74$ ani, au fost 28 pacienţi (10\% din total, 16 femei şi 12 bărbaţi).

În ceea ce priveşte localizarea arcadelor edentate, 61 pacienţi prezentau breşe edentate bimaxilare, iar 236 pacienţi prezentau breşe edentate unimaxilare.

La lotul studiat, în regiunea frontală maxilară, erau absenţi în medie 0,32 dinţi, cu un maximum de 2, în regiunea laterală maxilară erau absenţi în medie 2,57 dinţi, cu un maximum de 8, în regiunea frontală mandibulară erau absenţi în medie 0,21 dinţi, cu un maximum de 4, iar în regiunea laterală mandibulară erau absenţi în medie 2,61 dinţi, cu maximum de 8 (figura 1).
Numărul maxim de implanturi inserate în funcţie de zonele arcadelor dentare a fost similar $\mathrm{cu}$ numărul maxim de dinţi absenţi în fiecare regiune. Numărul de implanturi inserate în medie pe fiecare regiune a fost diferit în regiunile laterale faţă de numărul de dinţi absenţi, pentru că la unii pacienţi a fost inserat un număr mai mic de implanturi decât numărul de dinţi absenţi (2,54 implanturi inserate în medie la maxilar şi 2,39 implanturi inserate în medie la mandibulă) (figura 2).

Din analiza celor 297 fişe de consultaţie şi tratament, a rezultat că la respectivii pacienţi au fost inserate 1627 implanturi, dintre care 47 nu au avut o stabilitate secundară favorabilă protezării şi au fost explantate.

Încărcarea ocluzală a implanturilor s-a realizat tardiv, după o perioadă de minimum 6 luni la maxilar şi 3 luni la mandibulă. Protocoalele chirurgicale şi protetice au fost astfel realizate încât scoringul biomecanic iniţial pentru fiecare restaurare protetică a fost mai mic decât 2 .

Pe cele 1580 implanturi la care s-a produs osteointegrarea, au fost realizate 103 punţi cu agregare implantară (dintre care 64 cimentate şi 39 amovibile), 421 restaurări protetice de tip coroane solidarizate cu sprijin implantar (153 restaurări cimentate şi 268 restaurări amovibile) şi 289 coroane cu agregare implantară (83 cimentate şi 206 amovibile). După aplicarea restaurărilor protetice, pacienţii s-au prezentat la control din 6 în 6 luni în primul an şi, ulterior, anual.

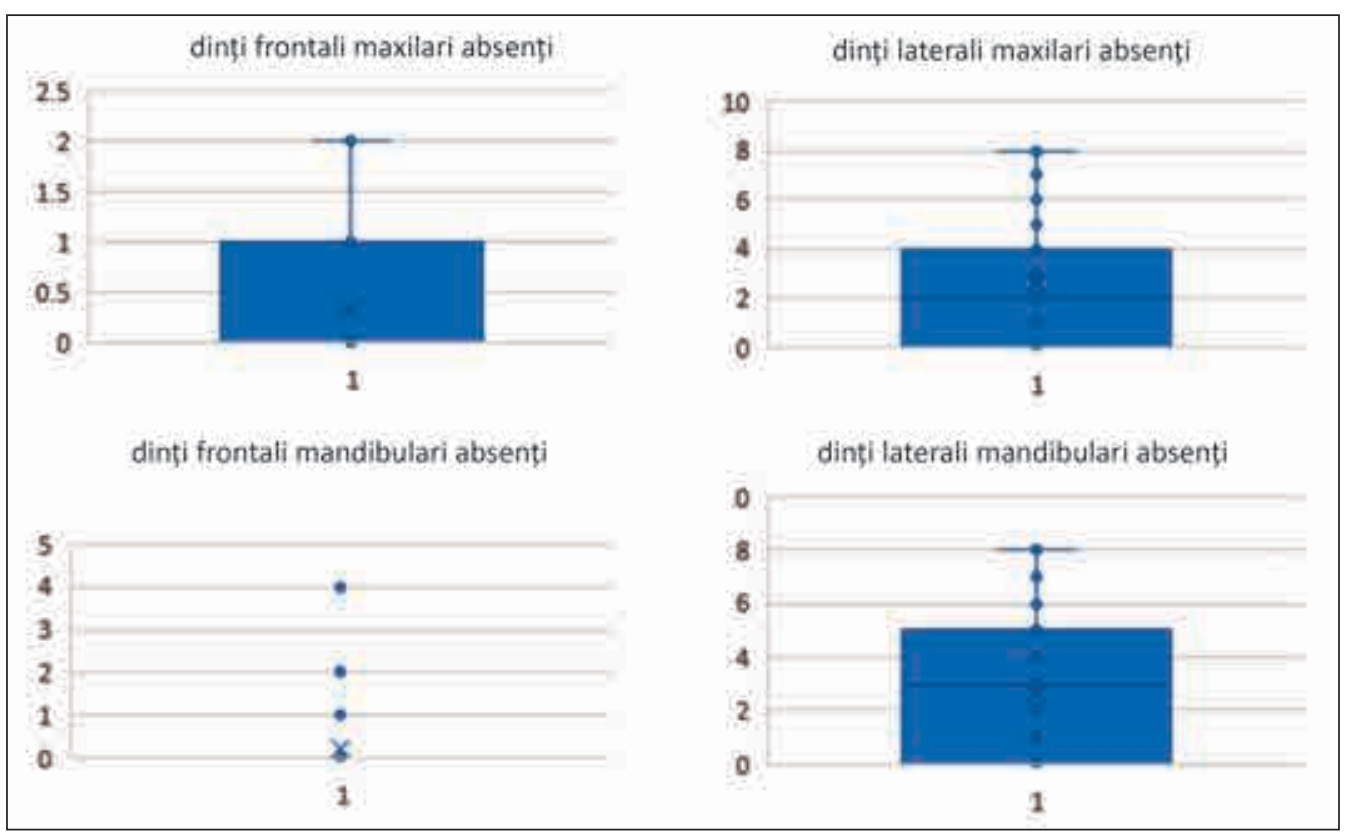

FIGURA 1. Distribuția medie a numărului de dinți absenți pe zone ale arcadelor dentare 


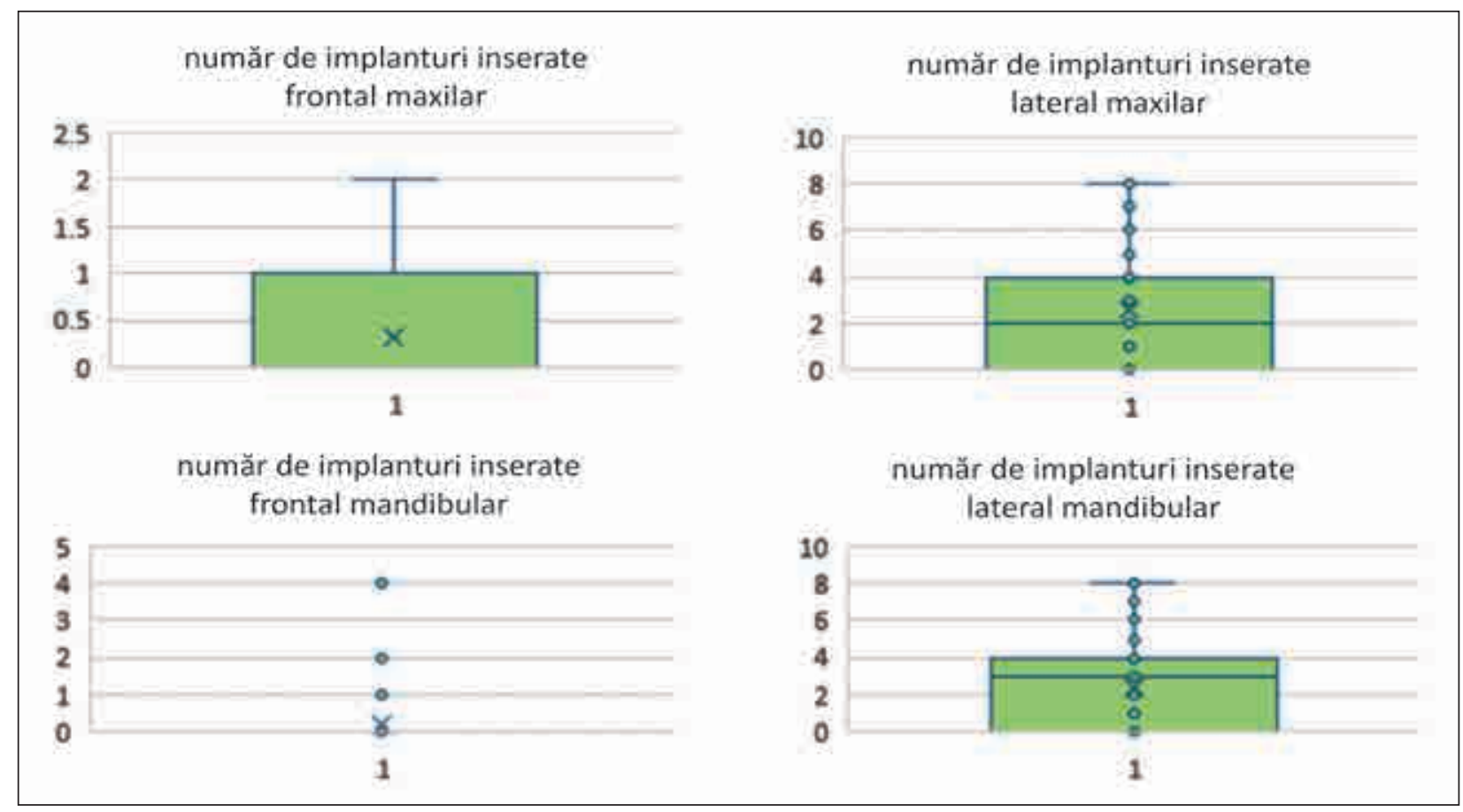

FIGURA 2. Distribuția medie a numărului de implanturi inserate pe zone ale arcadelor dentare

Complicaţiile terapiei implanto-protetice instituite au fost reprezentate de decimentare, slăbirea şuruburilor de fixare, fractura componentei fizionomice sau resorbţia osoasă ce trece de prima spiră a implantului, produse ca urmare a unor parafuncţii dezvoltate de pacienţi pe fond de stres, precum şi în urma unor dezechilibre ocluzale necorectate suficient sau apărute în timp prin pierderea unor dinţi vecini sau antagonişti restaurărilor cu agregare implantară.

Complicaţiile au fost constatate la 71 pacienţi dintre cei 297 , la momente diferite de timp după finalizarea tratamentelor protetice. Aceste incidente au reprezentat semnale de alarmă care au modificat scoringul biomecanic din verde în galben la 68 pacienţi, reprezentând $22,89 \%$ din total şi 95,77\% din numărul pacienţilor la care au apărut complicaţii terapeutice.
În figura 3 este ilustrată dependenţa dintre scorul biomecanic la 2 ani şi vârsta pacientului, care arată o tendinţă de evoluţie linear crescătoare cu vârsta.

În tabelul 1 este consemnată distribuţia modificărilor de scor biomecanic la 2 ani în funcţie de tipul de restaurare protetică efectuată, iar în tabelul 2 - distribuţia modificărilor de scor biomecanic în funcţie de tipul de complicaţie survenită la 2 ani la lotul analizat.

\section{DISCUȚII}

În etapa de planificare a tratamentului, pacientul va fi informat cu privire la riscurile intervenției chirurgicale şi limitele terapiei propuse, în scopul evitării eventualelor conflicte ulterioare.

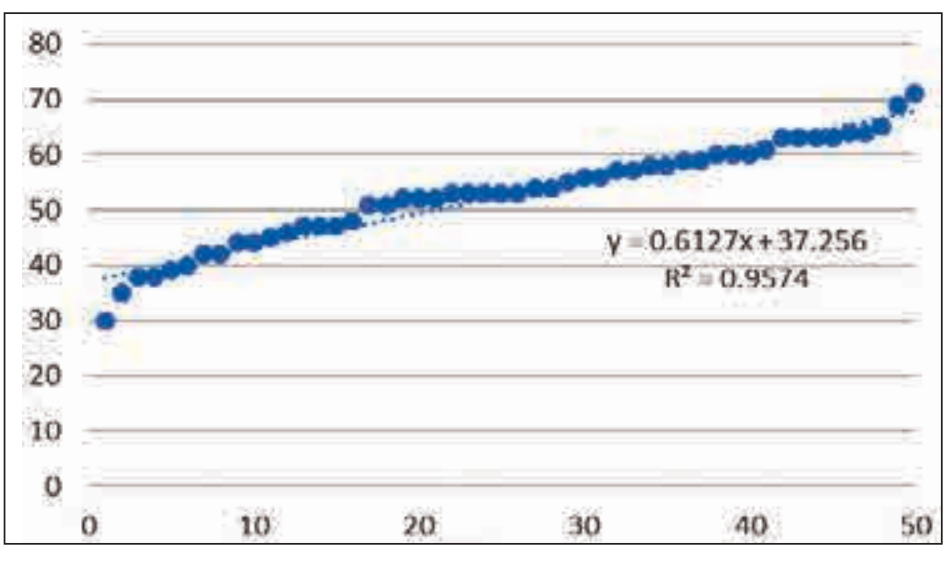

FIGURA 3. Dependența scorului biomecanic la 2 ani cu vârsta pacientului 
TABEL 1. Distributia modificărilor de scor biomecanic la 2 ani în funcție de tipul de restaurare protetică efectuată

\begin{tabular}{|c|c|c|c|}
\hline & & TOTAL & Procent \\
\hline \multicolumn{4}{|c|}{ coroane cimentate } \\
\hline & total & 83 & \\
\hline & are scor & 11 & $13,3 \%$ \\
\hline \multicolumn{4}{|c|}{ coroane amovibile } \\
\hline & total & 206 & \\
\hline & are scor & 11 & $5,3 \%$ \\
\hline \multicolumn{4}{|c|}{ coroane solidarizate cimentate } \\
\hline & total & 153 & \\
\hline & are scor & 19 & $12,4 \%$ \\
\hline \multicolumn{4}{|c|}{ coroane solidarizate amovibile } \\
\hline & total & 268 & \\
\hline & are scor & 13 & $4,9 \%$ \\
\hline \multicolumn{4}{|c|}{ punți cimentate } \\
\hline & total & 64 & \\
\hline & are scor & 11 & $17,2 \%$ \\
\hline \multicolumn{4}{|c|}{ punți amovibile } \\
\hline & total & 39 & \\
\hline & are scor & 3 & $7,7 \%$ \\
\hline
\end{tabular}

TABEL 2. Distribuția modificărilor de scor biomecanic în funcție de tipul de complicație survenită la 2 ani

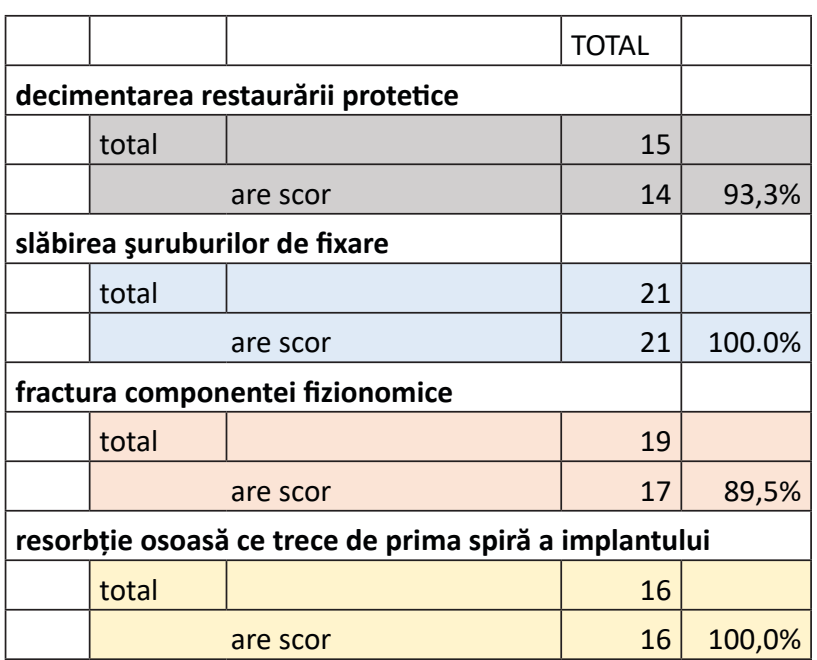

Apariţia unui număr tot mai mare de implanturi dentare şi tipuri de conexiuni protetice [6-9], tratamentul diferenţiat al suprafeţelor implantare [1012], îmbunătăţirea tehnicilor chirurgicale de inserare a implanturilor [13-15], a procedurilor de regenerare osoasă ghidată în scopul creşterii ofertei osoase disponibile [16-18], aprofundarea noţiunilor de biomecanică în implantologie [19], studiul biomaterialelor utilizate pentru protezare [21-23], cercetările cu privire la patologia periimplantară
[24-26] şi perfecţionarea tehnicilor imagistice preşi postoperatorii $[27,28]$ au contribuit semnificativ la predictibilitatea tratamentului implanto-protetic, ce presupune atât obţinerea unei osteointegrări adecvate, cât şi protezarea ulterioară corectă a implanturilor.

După identificarea riscurilor pe baza algoritmului propus de Renouard-Rangert [5], se pot încerca diminuarea sau chiar evitarea complicaţiilor utilizând anumite protocoale clinice. În acest sens, se poate ajusta planul terapeutic prin prelungirea etapei de vindecare după inserarea implanturilor $[29,30]$, selectarea implanturilor cu diametru crescut $[31,32]$, utilizarea unui număr mai mare de implanturi, alegerea unui implant cu design adecvat densităţii osoase din zona în care urmează să fie inserat, reducerea la minimum a numărului de unităţi masticatorii nesusţinute de un implant sau, uneori, contraindicarea restaurărilor implanto-protetice.

La lotul studiat, deşi scorul biomecanic Renouard-Rangert calculat iniţial a fost „în verde“, la 2 ani, s-a constatat apariţia complicaţiilor la 23,9\% dintre pacienţi, în principal din motive legate de dezvoltarea unor parafuncţii sau de modificări ale planului de ocluzie ca urmare a afectării dento-parodontale a altor unităţi masticatorii.

Modificarea scoringului biomecanic s-a întâlnit preponderent la femei (48 cazuri, reprezentând $67,6 \%)$.

Limitele studiului sunt date de numărul de persoane incluse în lotul analizat şi de perioada relativ redusă de monitorizare după încărcarea protetică a implanturilor. Pentru validarea rezultatelor, recomandăm extinderea lotului şi a perioadei de dispensarizare.

\section{CONCLUZII}

Procentul crescut de complicaţii terapeutice survenite la 2 ani care au determinat modificarea scorului biomecanic Renouard-Rangert (95,77\%) demonstrează o corelaţie semnificativă statistic între cei 2 parametri. Am constatat la lotul luat în studiu o tendinţă de evoluţie linear crescătoare a modificării scorului biomecanic la 2 ani în raport cu vârsta pacienţilor. 


\section{BIBLIOGRAFIE}

1. Moore R, Miller R, Henderson S. Risk management in oral surgery. Br Dent J. 2019 Dec;227(12):1035-1040.

2. Cervino G. Milestones of Dentistry: Advent of Anesthetics in Oral Surgery. Dent J (Basel). 2019 Dec 10;7(4):112.

3. Shi M, Han Z, Qin L et al. Risk factors for surgical site infection after major oral oncological surgery: the experience of a tertiary referral hospital in China. J Int Med Res. 2020 Aug;48(8):300060520944072.

4. Gupta R, Gupta N, Weber KK. Dental Implants. 2020 Aug 11. In: StatPearls. Treasure Island (FL): StatPearls Publishing; 2020.

5. Renouard F., Rangert B. Risk Factors in Implant Dentistry. Quintessence Publishing Co, 1999;29-38,39-66.

6. Ravidà A, Tattan M, Askar $\mathrm{H}$ et al. Comparison of three different types of implant-supported fixed dental prostheses: A long-term retrospective study of clinical outcomes and cost-effectiveness. Clin Oral Implants Res. 2019 Apr;30(4):295-305.

7. Wang $Q Q$, Dai $R$, Cao $C Y$ et al. One-time versus repeated abutment connection for platform-switched implant: A systematic review and meta-analysis. PLoS One. 2017 Oct 19;12(10):e0186385.

8. Elani HW, Starr JR, Da Silva JD, Gallucci GO. Trends in Dental Implant Use in the U.S., 1999-2016, and Projections to 2026. J Dent Res. 2018 Dec;97(13):1424-1430.

9. Almutairi AS, Walid MA, Alkhodary MA. The effect of osseodensification and different thread designs on the dental implant primary stability. F1000Res. 2018 Dec 5;7:1898.

10. Czumbel LM, Kerémi $B$, Gede $N$ et al. Sandblasting reduces dental implant failure rate but not marginal bone level loss: A systematic review and meta-analysis. PLoS One. 2019 May 3;14(5):e0216428.

11. Carmo Filho LCD, Marcello-Machado RM, Castilhos ED et al. Can implant surfaces affect implant stability during osseointegration? A randomized clinical trial. Braz Oral Res. 2018 Oct 25;32:e110.

12. Hafezeqoran A, Koodaryan R. Effect of Zirconia Dental Implant Surfaces on Bone Integration: A Systematic Review and MetaAnalysis. Biomed Res Int. 2017;2017:9246721.

13. Jia LM, He JX, Lu JY et al. [Precise implant insertion technology for measuring dental implant placement]. Hua Xi Kou Qiang Yi Xue Za Zhi. 2020 Feb 1;38(1):108-113.

14. Sasaki H, Hirano T, Nomoto $\mathrm{S}$ et al. Dental Implant Treatment with Computer-assisted Surgery for Bilateral Agenesis of Maxillary Lateral Incisors: A Case Report. Bull Tokyo Dent Coll. 2018; 59(1):43-51.

15. Sawase T, Kuroshima S. The current clinical relevancy of intraoral scanners in implant dentistry. Dent Mater J. 2020 Jan 31; 39(1):57-61.

16. Vikhe DM, Shah SV, Carrion JB, Palekar UG. Innovative method "DV-PIMS" technique and dental implant design for grafting injectable platelet-rich fibrin around the dental implant - Goat jaw cadaver study. Indian J Dent Res. 2019 May-Jun;30(3):450-454.

17. Gupta B, Shadbolt B, Hyam D. Referral patterns of general dental practitioners for bone grafting and implant placement. Aust Dent $\mathrm{J}$. 2017 Sep;62(3):311-316.

18. Raţiu $C A, B o s ̧ c a A B$, Cavalu $S$ et al. Two case reports of vertical and horizontal augmentation with autogenous bone blocks; seven years follow-up. Rom J Morphol Embryol. 2019;60(1):261-266.
19. Gan XQ, Xiao Y, Ma RY et al. [Expert consensus on biomechanical research of dental implant]. Hua Xi Kou Qiang Yi Xue Za Zhi. 2019 Apr 1;37(2):115-123.

20. Comăneanu RM, Hancu V, Barbu HM et al. Comparative assessment of biocompatibility of $\mathrm{NiCr}$ and $\mathrm{CoCr}$ alloys used in metal-fused-to-ceramic technology. Rev Chim. (Bucharest) 2015; 66(3):312-315.

21. Drăguș $L$, Ghergic $D L$, Comăneanu RM et al. In vitro comparative tests about the biocompatibility of some dental alloys. Rev Chim. (Bucharest) 2019;70(2):610-613.

22. Tarcolea M, Hancu V, Miculescu F et al. Research on microstructural and chemical inhomogeneity in cast metal crowns made of CoCrMoW alloy. Revista de Chimie 2015;66(8):1143-1146.

23. Hancu V, Comăneanu RM, Coman C et al. Microstructure and Chemical Homogeneity of Cast Dental Crowns Made from CoCrMoW Alloy and Ceramic Mass. Revista de Chimie 2015; 66(9):1327-1330.

24. Insua A, Monje A, Wang HL, Miron RJ. Basis of bone metabolism around dental implants during osseointegration and peri-implant bone loss. J Biomed Mater Res A. 2017 Jul;105(7):2075-2089.

25. French D, Grandin HM, Ofec R. Retrospective cohort study of 4,591 dental implants: Analysis of risk indicators for bone loss and prevalence of peri-implant mucositis and peri-implantitis. J Periodontol. 2019 Jul;90(7):691-700.

26. Chin JS, Rees J, Locke M, Addy LD. Maintaining peri-implant health: an evaluation of understanding among dental hygienists and therapists in Wales. Br Dent J. 2019 Jun;226(11):867-870.

27. Tavelli L, Borgonovo AE, Re D, Maiorana C. Sinus presurgical evaluation: a literature review and a new classification proposal. Minerva Stomatol. 2017 Jun;66(3):115-131.

28. Garlapati K, Babu DBG, Chaitanya NCSK et al. Evaluation of Preference and Purpose of Utilisation of Cone Beam Computed Tomography (CBCT) Compared to Orthopantomogram (OPG) by Dental Practitioners - A Cross-Sectional Study. Pol J Radiol. 2017 May 4;82:248-251.

29. Bassir SH, El Kholy K, Chen CY et al. Outcome of early dental implant placement versus other dental implant placement protocols: A systematic review and meta-analysis. J Periodontol. 2019 May; 90(5):493-506.

30. Chen J, Cai M, Yang J et al. Immediate versus early or conventional loading dental implants with fixed prostheses: A systematic review and meta-analysis of randomized controlled clinical trials. J Prosthet Dent. 2019 Dec;122(6):516-536.

31. Hsu JT, Shen YW, Kuo CW et al. Impacts of 3D bone-to- implant contact and implant diameter on primary stability of dental implant. J Formos Med Assoc. 2017 Aug;116(8):582-590.

32. Duan Y, Gonzalez JA, Kulkarni PA et al. Fatigue lifetime prediction of a reduced-diameter dental implant system: Numerical and experimental study. Dent Mater. 2018 Sep;34(9):1299-1309. 